\title{
Unproven / Alternative Methods of Treating Allergic Rhinitis
}

\author{
Sumit Sharma* \\ Department of ENT, Mayo Institute of Medical Sciences, India
}

Submission: June 16, 2016; Published: January 03, 2017

*Corresponding author: Sumit Sharma, Department of ENT, Royale Medical Centre, L 3/67, Sector-D, Near Happy World Girls College, Aliganj, Lucknow, 226024, Tel: 9839178240; Email: entsumit@rediffmail.com

\section{Editorial}

Allergic rhinitis, also known as hay fever, is a type of inflammation in the nose which occurs when the immune system overreacts to allergens in the air [1]. Signs and symptoms include a runny or stuffy nose, sneezing, red, itchy, and watery eyes, and swelling around the eyes [2]. The fluid from the nose is usually clear. Symptoms onset is often within minutes following exposure and they can affect sleep, the ability to work, and the ability to concentrate at school [3]. A number of treatment modalities have been used like topical decongestants, mast cell stabilizers and steroids to systemic decongestants, mast cell stabilizers, anti-allergic and steroids. Sometimes even surgical options are considered but some patients continue to have symptoms and live with significant morbidity. Complementary and alternative medicine (CAM) therapies for allergic rhinitis and conjunctivitis include Chinese herbal medicine (CHM), Ayurvedic medicine, other single and multiple herb preparations, acupuncture, homeopathy, and several other modalities. CAM therapies continue to gain popularity in the United States and throughout the world for the treatment of asthma and allergies [4].

Complementary and alternative medicine (CAM) is commonly defined as a group of diverse medical and healthcare systems, practices, and products that are not generally considered part of the conventional allopathic medical practices. Complementary therapies are used together with conventional allopathic medicine, while alternative therapies are used in place of conventional medicine [4]. The use of CAM is growing in Western countries because of the reputed effectiveness, low cost, and favorable safety profiles of some therapies. Patients are often interested in alternative therapy either because conventional therapies are unsatisfactory or because of concerns about side effects of synthetic drugs [4]. The chronic nature of allergic diseases and the paucity of preventive or curative treatments also stimulate interest in CAM therapies [5]. This article reviews some of the Complementary and alternative medicine (CAM) therapies for allergic rhinitis like Ayurveda, Homeopathy,
Acupressure, Nasal saline wash, and a few others, they are not suggested as a definite line of treatment for allergic rhinitis and more research is needed to establish their role in this condition.

\section{Ayurveda}

Ayurvedic medicine is a medical tradition originating from India and derived from the teachings of ancient Hindu healers, which first appeared in text between 1500 and 1000 BC. Ayurveda exists for the «promotion of health» rather than the treatment of specific disease states that have already begun to affect the body [4]. Ayurvedic herbal therapies have been evaluated in the treatment of allergic rhinitis. Aller-7 is a mixture of seven Indian herbs (Albizia lebbeck, Terminalia chebula, Terminalia bellerica, Phyllanthus emblica, Piper nigrum, Piper longum, and Zingiber officinale). In vitro studies examining the mixture demonstrated antihistaminic and anti-inflammatory properties [5] and were found to be equivalent to cetirizine. Tinospora cordifolia extracts a study conducted by VA Badar et al. [6] showed that it significantly decreased all symptoms of allergic rhinitis. Nasal smear cytology and leukocyte count correlated with clinical findings. TC was well tolerated.

\section{Homeopathy}

Homeopathy is best placed to treat all sorts of allergic disorders. The reason for this is that it does not try to treat the symptoms of the allergies. Instead, it works to root out the cause of these allergies. The root cause in allergies happens to be a hyperactivity of the immune system. This hyperactive immune system goes into an overdrive when it comes in contact with certain things, the homeopathic medicines repair the immune system and the hyperactivity is corrected. Then the body reacts normally to the same things that used to cause the allergies [7] 5 best Homeopathic medicines for Allergic Rhinitis or Hay Fever are [8].

\section{Allium Cepa - for watery eyes \\ Arsenic Album - for intense thirst}


Natrum Mur - for excessive sneezing

Merc Sol - for sensitivity to heat and cold

Arundo - for intense itching

Two medicines which represent new advance in homeopathy are Galphimia Glauca and Histaminum Hydrochlo-ride. A US study found Galphimia Glauca to be highly effective in treating allergic rhinitis. Many other very effective plant-based medicines have also been introduced during the last few years: Cardiospermum Halicacabum and Amni Visnaga. It is important to remember that homoeopathy is a system where the treatment is based on the patient's individual symptoms. Thus, each medicine has its own important place in treating allergic rhinitis. It may take a season or two to completely cure allergic rhinitis [9].

\section{Acupuncture and Acupressure}

Acupuncture is a component of traditional Chinese medicine (TCM) that was originally thought to work on the principle of redistribution of Qi, the life energy. In TCM, disease is believed to originate from an imbalance of Qi or poor flow of Qi [4]. Studies of acupuncture for the treatment of allergic rhinitis have shown mixed results, with the most rigorous studies showing very modest clinical benefit [4]. In summary, the best trials of acupuncture for allergic rhinitis support limited benefit. Despite this, acupuncture may be a reasonable option for interested patients with relatively mild disease who wish to minimize medication use and find the cost of therapy acceptable [4].

Acupressure is a form of touch therapy that utilizes the principles of acupuncture and Chinese medicine. In acupressure, the same points on the body are used as in acupuncture, but are stimulated with finger pressure instead of with the insertion of needles. Acupressure is used to relieve a variety of symptoms [10]. Stainless steel pellets in adhesive discs are applied to specified points (acupoints) on the ear, and the pellets are pressed firmly into the skin [11]. A study was conducted by Zhang CS et al. [11] on this and there was a small but statistically significant improvement in sneezing and quality of life in the acupressure group after eight weeks, with additional improvements in most measures of nasal symptoms at the end of the follow-up period compared with the sham group

\section{Nutrition}

A study conducted by Dr. Lisa Lewis, ND, Lac [12,13] suggested that to reduce allergy symptoms, eat a moderately low-fat, high-complex-carbohydrate diet. Drink $1 / 2$ of body weight in ounces of water daily (e.g., a $150 \mathrm{lb}$ person would drink $75 \mathrm{oz}$ of water) [9].

\section{a) Include a lot of the following foods in the diet:}

Dark green, leafy vegetables / Deep yellow and orange vegetables / Nettles, bamboo shoots, cabbage, beet tops, beets, carrots, yams / Onions, garlic, ginger, cayenne, horse radish and

\section{b) Eliminate the following from the diet:}

Alcohol, caffeine, and dairy products / Bananas and citrus fruit / Chocolate / Food colorings (tartrazine) / Peanuts / Red meat / Sugar / Wheat and

c) Supplement Vitamins and Minerals in diet like Bioflavonoid, / Flaxseed oil / Probiotics / Vitamin A / Vitamin C / Vitamin E and Zinc.

\section{Nasal Irrigation}

Saline nasal irrigation (SNI) is often recommended as additional nonpharmacologic treatment, having proven its efficacy in acute and chronic rhino sinusitis and for therapy after Sino nasal surgery. To date, however, no systematic review or meta-analysis exists showing the influence of SNI on allergic rhinitis (AR). A study conducted by Hermelingmeier KE et al. [9] showed that Saline nasal irrigation using isotonic solution can be recommended as complementary therapy in AR. It is well tolerated, inexpensive, easy to use, and there is no evidence showing that regular, daily SNI adversely affects the patient's health or causes unexpected side effects.

\section{Conclusion}

Although the topical and systemic decongestants, antiallergics, mast cell stabilizers, steroids along with immunotherapy remain the main stray of treatment of Allergic Rhinitis, these alternative unproven methods of treating allergic rhinitis can be of some help in those patients who remain symptomatic even after treatment and also to improve quality of life.

\section{References}

1. Immunotherapy for Environmental Allergies (2015) NIAID.

2. Environmental Allergies: Symptoms (2015) NIAID.

3. Wheatley LM, Togias A (2015) Clinical practice. Allergic rhinitis. N Engl J Med372 (5): 456-463.

4. Leonard Bielory, Jonathan Corren, Anna M Feldweg. Complementary and alternative therapies for allergic rhinitis and conjunctivitis

5. Amit A, Saxena VS, Pratibha N (2003) Mast cell stabilization, lipoxygenase inhibition, hyaluronidase inhibition, antihistaminic and antispasmodic activities of Aller-7, a novel botanical formulation for allergic rhinitis. Drugs Exp Clin Res 29: 107.

6. Badar VA, Thawani VR, Wakode PT, Shrivastava MP, Gharpure KJ, et al. (2005) Efficacy of Tinospora cordifolia in allergic rhinitis. J Ethnopharmacol 96(3): 445-449.

7. Harsh Sharma (2014) Best Homeopathic medicines for Allergic Rhinitis.

8. Heimall J, Bielory L (2004) Defining complementary and alternative medicine in allergies and asthma: benefits and risks. Clin Rev Allergy Immunol 27(2): 93-103.

9. Vikas Sharma (2014) Allergic Rhinitis and Homeopathy Treatment

10. Acupressure Dictionary, Thesaurus, Wikipedia.

11. Zhang CS, Xia J, Zhang AL (2014) Ear acupressure for perennial allergic rhinitis: A multicenter randomized controlled trial. Am J Rhinol Allergy 


$$
\text { 28: e152. }
$$

12. Natural Treatments for Your Seasonal Allergies By Dr. Lisa Lewis, ND, Lac
13. Hermelingmeier KE, Weber RK, Hellmich M, Heubach CP, Mösges R. Nasal irrigation as an adjunctive treatment in allergic rhinitis: a systematic review and meta-analysis. Am J Rhinol Allergy 26(5): 119125.

Your next submission with JuniperPublishers will reach you the below assets

- Quality Editorial service

- Swift Peer Review

- Reprints availability

- E-prints Service

- Manuscript Podcast for convenient understanding

- Global attainment for your research

- Manuscript accessibility in different formats ( Pdf, E-pub, Full Text, Audio)

- Unceasing customer service

Track the below URL for one-step submission https://juniperpublishers.com/online-submission.php 